EXTENDED REPORT

\title{
Direct costs related to rheumatoid arthritis: the patient perspective
}

\author{
J L Hülsemann*, T Mittendorf, S Merkesdal, S Zeh, S Handelmann, J- M von der \\ Schulenburg, H Zeidler, J Ruof*
}

See end of article for authors' affiliations

Correspondence to: Dr J L Hülsemann, Division of Rheumatology, Hannover Medical School, Hannover, Germany CarlNeuberg-Str 1, D-30625 Hannover, Germany; huelsemann.jan@mhhannover.de

Accepted 21 March 2005 Published Online First 30 March 2005

\begin{abstract}
Objective: To determine rheumatoid arthritis related out of pocket expenditure (OOPE) in Germany and to disaggregate the total OOPE into contributing cost domains.

Methods: Data for the cost analysis were drawn from a multicentre randomised controlled prospective trial to assess the effectiveness of clinical quality management in patients with rheumatoid arthritis. Both payer sources and patient cost questionnaires were used to generate health care utilisation data. All cost domains of a recently published matrix were reviewed and potential sources of OOPE were determined. Health care utilisation data were developed throughout 2001. Co-payment regulations as per January 2004 were applied in order to indicate the most recent level of OOPE in Germany. Data were analysed in both physical and monetary units using descriptive statistics.

Results: In all, 136 patients with rheumatoid arthritis were included. Mean total OOPE per patient and year was $€ 417.20$ (SEM 38.8, median 271.2). OOPE accounted for $15.3 \%$ of the total direct costs of rheumatoid arthritis. Total OOPE were further subdivided into cost domains: "non-physician service utilisation"' (€194.40 per patient and year; SEM 24.2), "medication" (€99.00; 6.1), "transportation" $(€ 56.20 ; 17.4)$, "visits to physicians" (€38.40; 0.6), "hospital facilities" (€24.00; 5.6), and "devices and aids" (€5.10;0.8).

Conclusions: Rheumatoid arthritis is associated with substantial OOPE, imposing a considerable economic burden for patients. OOPE contribute significantly to the total health care expenditure in rheumatoid arthritis. The patient perspective has to be taken into account when calculating the overall direct costs of rheumatoid arthritis from a societal point of view.
\end{abstract}

$\mathrm{P}$ atient out of pocket expenditure (OOPE) covers an important part of total health care costs. Respective studies in the USA indicate that OOPE for deductibles, co-payments, and payment of uncovered services accounts for approximately $20 \%$ of total health care expenditure, with an increasing trend. ${ }^{1}$ In particular, in patients with chronic conditions this results in a substantial burden for patients and their families. ${ }^{23}$

Although the number of published reports on cost of illness in rheumatoid arthritis has increased considerably over the past decade ${ }^{4-6}$ most of the studies have applied a societal or a payer perspective and have not specifically addressed OOPE. Only few studies have examined OOPE in rheumatic conditions: Boonen et al examined OOPE in 209 patients with ankylosing spondylitis and reported an average annual healthcare and non-healthcare expenditure of $€ 431$ per patient; Lapsely et $a l^{8}$ reported particularly high OOPE for patients with advanced osteoarthritis, especially women in Australia; Lapsley et al ${ }^{9}$ examined rheumatoid arthritis related OOPE in Australia and found an average annual spending of \$A1513 ( €893; exchange rate as per July 2004: $1 €=0.59 \mathrm{~A} \$$ ); in an early study by Liang et al, ${ }^{10}$ the fraction covered by patient OOPE was estimated to account for at least $20 \%$ of total rheumatoid arthritis related direct costs; and finally, in a study by Cooper et al, ${ }^{11}$ individuals with early inflammatory polyarthritis incurred a mean expenditure of $£ 1297$ over a six month period.

So far no data on rheumatoid arthritis related OOPE in a continental European country have been published. In addition, the composition of OOPE and the contribution of individual cost domains to the total OOPE is not clear. Thus the aim of our study was to determine the rheumatoid arthritis related OOPE in Germany and to disaggregate the total OOPE into the contributing cost domains.

\section{METHODS}

\section{Original study and patient characteristics}

Data for the cost analysis were drawn from the findings of a multicentre randomised controlled prospective trial to assess the effectiveness of clinical quality management in patients with rheumatoid arthritis. ${ }^{12}{ }^{13}$ Inclusion criteria for the trial were: fulfilment of ACR classification criteria for rheumatoid $\operatorname{arthritis}^{14}$; age over 18 years; having had at least one consultation with a rheumatologist; and insurance through the Allgemeine Ortskrankenkasse Niedersachsen (AOKN), a major statutory health insurance company. Written consent was required. Subjects were recruited by 14 outpatient rheumatologists in private practice in the state of Lower Saxony, Germany.

Both the clinical trial and the costing study involved collaboration between the AOKN, the Kassenärztliche Vereinigung Niedersachsen $(\mathrm{KVN})$, and the Hannover Medical School. The AOKN is a health insurance organisation that covers medical care for 2.3 million members in Lower Saxony. The KVN is the regional physicians' association. The Social Ministry of Lower Saxony approved data transfer procedures and data protection measures. The study design was approved by the local ethics committee of the Hannover Medical School. Details of the approach are described elsewhere. ${ }^{15}{ }^{16}$

Abbreviations: AOKN, Allgemeine Ortskrankenkasse Niedersachsen; KVN, Kassenärztliche Vereinigung Niedersachsen; OOPE, out of pocket expenditure 


\section{Generation of cost data}

Two main sources of cost data were applied to determine the level of OOPE:

- Payer data sources (AOKN and KVN) were used to generate health care utilisation data for the period of January 2001 to December 2001. A patient per patient microcosting approach was carried out. ${ }^{16}$

- In addition, a patient questionnaire was developed and applied. ${ }^{17}$ The questionnaire was completed by patients at baseline and then once per quarter throughout 2001. The first form was filled in at the physician's office, and the following three questionnaires were sent by mail. A monitoring system was established to ensure that patients were reminded to return forms if necessary. Within the questionnaire, patients were instructed to report rheumatoid arthritis related health care utilisation only.

The cost analysis was structured according to the recently published matrix of cost domains in rheumatoid arthritis. ${ }^{18}$ Based on the perspective of the study (patients' perspective) all cost domains were reviewed and potential sources of OOPE were determined. The identified sources of OOPE as well as the data sources applied to develop those data are given in table 1 . It has to be noted that because of efforts to limit public health care expenditure, the co-payment regulations in Germany changed in January 2004. To indicate the most recent level of co-payment we determined the healthcare utilisation as per 2001, but linked it to the co-payment regulations as per January 2004. Details are shown in the Remarks column in the table 1.

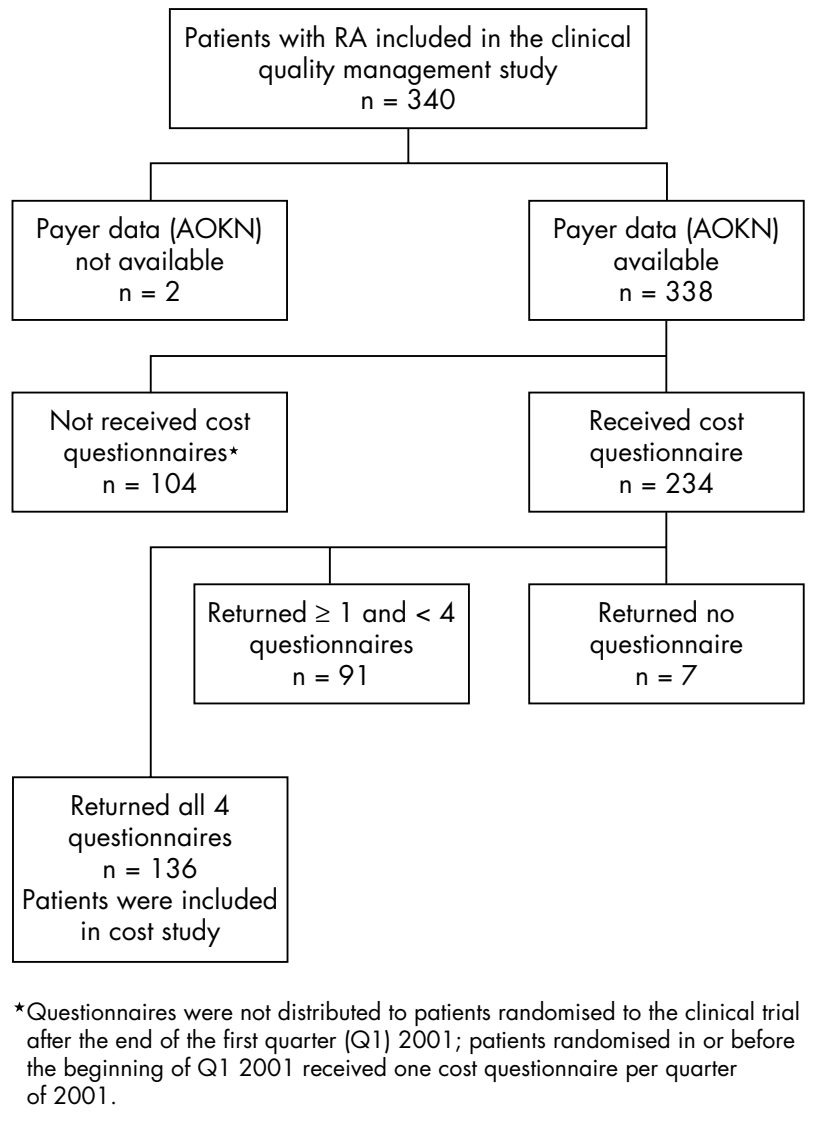

Figure 1 Algorithm for patients recruited for the cost study.

\section{Sensitivity analysis and data management}

In addition to the base case scenario a sensitivity analysistaking into account the range of possible co-payments (see the table 1)—was conducted for the following domains:

- Non-physician service utilisation: base case: co-payment $€ 7.50$; sensitivity analysis: low case co-payment $€ 5$; high case co-payment $€ 10$.

- Medication: base case: co-payment for all rheumatoid arthritis related drug treatment $€ 7.50$; sensitivity analysis: low case co-payment for all rheumatoid arthritis related drug treatment $€ 5$; high case: co-payment for disease modifying antirheumatic drugs (DMARD) €10; and for all other rheumatoid arthritis related drug treatment copayment $€ 7.50$.

- Devices and aids: base case: $€ 7.50$ co-payment; sensitivity analysis: low case co-payment $€ 5$; high case co-payment $€ 10$.

Data management was carried out on Microsoft ACCESS software (version 8.0). For data analysis SPSS version 10.0 was used. For the purpose of the current study only descriptive statistics were applied. ${ }^{19}$ Data were analysed in both physical and monetary units.

\section{RESULTS}

\section{Demographics and data collection}

In all, 340 patients participated in the clinical trial. Health care utilisation questionnaires were sent to a randomly selected sample of 234 patients (67\%). Over the course of the year 2001 four questionnaires (one per quarter) were distributed per patient; 227 patients returned at least one of the four questionnaires and complete sets of four consecutive questionnaires were returned by 136 respondents. The analysis was limited to those 136 patients. As has been shown previously in a sensitivity analysis, the exclusion of the remaining 91 patients who did not return all the questionnaires did not bias the reported health care utilisation. ${ }^{17}$ The complete set of payer derived cost data (through AOKN and KVN) was generated and matched to the same sample of 136 patients. The patient flow is shown in fig 1 . Demographic characteristics of the patient cohort included in the present study are shown in table 2 .

\section{OOPE per cost domain}

The mean total OOPE per patient and year was $€ 417.20$ (SEM 38.8, median 271.2). A breakdown of total OOPE into the individual cost domains is shown in fig 2. The two most relevant cost domains were "non-physician service utilisation" and "medication".

\section{Visits to physicians}

Over the course of the year the 136 patients incurred a total of 3796 physician visits. The mean number of visits was 28 (SEM 1.7) per patient and year (median 23). In Germany a $€ 10$ co-payment is required only for the first physician visit per quarter. The respective data are given in table 3 (physical units) and table 4 (monetary units).

Non-physician service utilisation

In 2001 the patient cohort incurred a total of 3526 nonphysician service visits (mean (SEM), 25.9 (3.2); median 12.0). A subdivision into the various services used is given in table 3 . The respective monetary units are displayed in table 4. The cost domain "non-physician service utilization" accounted for almost half the total OOPE (47\%). 
Table 1 Out of pocket expenditure (OOPE) per cost domain and the respective data sources

\begin{tabular}{|c|c|c|}
\hline Cost domains & Remarks & Utilisation data source \\
\hline \multicolumn{3}{|l|}{ Outpatient costs } \\
\hline Visits to physicians & $\begin{array}{l}\text { From January 2004, patients have to pay a fee of } € 10 \text { per quarter when } \\
\text { incurring a physician visit. }\end{array}$ & $\mathrm{KVN}$ \\
\hline $\begin{array}{l}\text { Non-physician service } \\
\text { utilization }\end{array}$ & $\begin{array}{l}\text { Including unconventional medicine (natural healers), physiotherapy, } \\
\text { balneotherapy, occupational therapy, and psychological therapy with a } \\
\text { minimum of } € 5 \text { and a maximum of } € 10 \text { per prescription. }\end{array}$ & Patient questionnaire \\
\hline Medication & $\begin{array}{l}\text { Prescription related co-payment of } 10 \% \text { of pharmacy price, with a minimum of } \\
€ 5 \text { and a maximum of } € 10 \text { per prescription. }\end{array}$ & $\begin{array}{l}\text { AOKN } \\
\text { Disaggregation based on PZN code } \\
\text { ("Pharmazentralnummer") }\end{array}$ \\
\hline Devices and aids & $\begin{array}{l}\text { Includes devices and aids with a minimum of } € 5 \text { and a maximum of } € 10 \text { per } \\
\text { prescription. }\end{array}$ & Patient questionnaire \\
\hline \multicolumn{3}{|l|}{ Inpatient costs } \\
\hline Hospital facilities & Hospital admission fees of $€ 10 /$ day for maximum of 28 days per year & $\begin{array}{l}\text { AOKN } \\
\text { Identification of rheumatoid arthritis related } \\
\text { admissions based on ICD-10 admission codes }\end{array}$ \\
\hline \multicolumn{3}{|c|}{ Other disease related costs (direct) } \\
\hline Transportation & Covered by patients since January 2004 & AOKN \\
\hline
\end{tabular}

\section{Medication}

OOPE for medication was identified as the second most costly cost domain and accounts for $24 \%$ of total OOPE (table 4 ). A subdivision into the various rheumatoid arthritis related drug classes as well as the respective physical consumption units is shown in table 3.

\section{Devices and aids}

In all, 93 devices and aids were used. The respective numbers (number of devices and aids used) per patient and year were: mean (SEM), 0.7 (0.1); median 0 . The most frequently used aids and devices were: special footwear $(n=28)$, reconstruction work at home $(\mathrm{n}=14)$, collar $(\mathrm{n}=14)$, bandage $(\mathrm{n}=11)$, and canes and crutches $(\mathrm{n}=9)$.

\section{Hospital facilities}

Twenty patients (15\%) incurred inpatient costs. The total number of inpatient days was 357. One patient had an inpatient episode of 58 days; all other inpatient episodes were less than 28 days. As co-payment is required only for a maximum of 28 days the total amount of co-payment was [357 days minus 30 days] $\times € 10=€ 3270$. The number of inpatient days per patient and year were: mean (SEM), 2.4 (0.6); median 0 .

Table 2 Demographic, clinical, and social variables of the 136 patients with rheumatoid arthritis included in the analysis

\begin{tabular}{ll}
\hline Demographic variables & \\
Female & $77 \%$ \\
Age (years) & $57.4(12.5)$ \\
& \\
Clinical variables & $8.2(8.4)$ \\
Disease duration (years) & $5.5(6.2)$ \\
No of swollen joints & $16(17)$ \\
ESR (mm/h) & $60.3 \%$ \\
Rheumatoid factor positivity (\%) & $60 \%$ \\
Erosive changes (\%)* & \\
& \\
Social variables & $24 \%$ \\
Currently employed & $48 \%$ \\
Retired & $43 \%$ \\
Apprenticeship as highest educational level & $2 \%$ \\
University degree as highest educational level & \\
\hline & \\
Values are \% or mean (SD). & \\
*On $x$ rays of hands and feet; data for 11 patients missing. \\
ESR, erythrocyte sedimentation rate.
\end{tabular}

\section{Transportation}

In all, 334 transportation trips were employed. Only 27 patients $(20 \%)$ incurred transportation trips. The data, however, appeared very skewed as three patients accounted for transportation costs of more than $€ 1000$ each, while the total amount of transportation costs for all patients was $€ 7647$.

\section{Sensitivity analysis}

A sensitivity analysis was conducted for three cost domains: "non-physician service utilisation", "medication", and "aids and devices". Table 5 gives the data for "non-physician service utilisation" and "medication". The mean (SEM) for "devices and aids" were: low case, €3.40 (0.5); and high case, $€ 6.80(1.0)$.

\section{DISCUSSION}

Rheumatoid arthritis is a chronic disease with substantial total direct disease related costs, which amount to $€ 2729$ per patient and year from a societal perspective, with $€ 417$ (15.3\%) being paid by the patients as OOPE (data presented in this study) and $€ 2312(84.7 \%)$ being covered by the payers. ${ }^{16}$

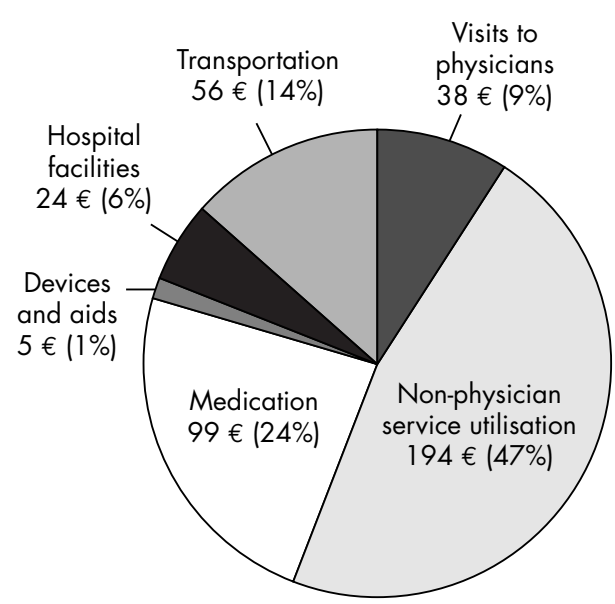

Figure 2 Rheumatoid arthritis related out of pocket expenditure (OOPE) per year by cost domains depicted as $€$ costs (\% of total OOPE). 
Table 3 Sources of rheumatoid arthritis related co-payment in physical units (only cost domains with costs of $>€ 10$ )

\begin{tabular}{|c|c|c|c|}
\hline Cost domain & \multicolumn{3}{|l|}{ Physical units } \\
\hline Visits to physicians & \multicolumn{3}{|c|}{$\begin{array}{l}\text { - } 126 \text { patients incurred physician visits in all four quarters } \\
4 \text { patients incurred physician visits in three quarters } \\
\text { - } 6 \text { patients incurred physician visits in two or fewer quarters }\end{array}$} \\
\hline Non-physician service utilisation & \multicolumn{3}{|c|}{ 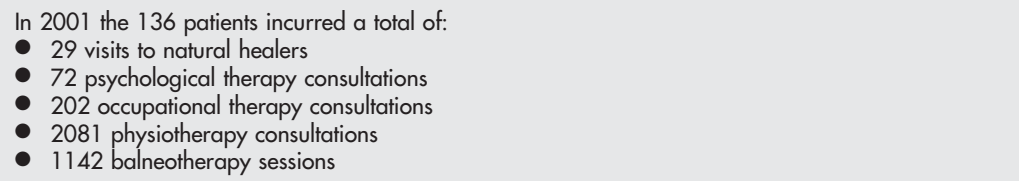 } \\
\hline Medication & $\begin{array}{l}\text { No of patients receiving } \\
\text { respective treatment: }\end{array}$ & $\begin{array}{l}\text { Average No of prescriptions } \\
\text { per year (SEM) }\end{array}$ & $\begin{array}{l}\text { Median No of prescriptions } \\
\text { per year }\end{array}$ \\
\hline DMARD & 116 & $4.7(0.5)$ & 3.5 \\
\hline Steroids & 106 & $3.0(0.2)$ & 3.0 \\
\hline NSAID & 99 & $2.8(0.3)$ & 2.0 \\
\hline Osteoporosis medication & 81 & $1.8(0.2)$ & 1.0 \\
\hline Analgesics & 41 & $0.9(0.2))$ & 0 \\
\hline Devices and aids & \multicolumn{3}{|c|}{$\begin{array}{l}\text { - } 50 \text { patients used aids and devices in } 2001 \\
\text { - } 93 \text { devices and aids were used in all }\end{array}$} \\
\hline Hospital facilities & \multicolumn{3}{|c|}{$\begin{array}{l}\text { - } 15 \% \text { of patients }(n=20 \text { ) incurred inpatient costs } \\
357 \text { inpatient days were used in all } \\
\text { - Patients had to pay a } 10 € / \text { day co-payment fee for a total of } 327 \text { inpatient days }\end{array}$} \\
\hline Transportation & \multicolumn{3}{|c|}{$\begin{array}{l}\text { - } 27 \text { patients incurred transportation costs } \\
\text { - } 334 \text { trips were used in all }\end{array}$} \\
\hline
\end{tabular}

Data from the United States indicate that OOPE account for at least $20 \%$ of the direct health care costs. ${ }^{10}$ Our data from a German perspective indicate a slightly lower percentage (around 15\%) of total direct health care costs that are covered by patients as OOPE. While our data showed a rheumatoid arthritis related OOPE of $€ 417$ per patient and year, recent estimates from Australia are also considerably higher (\$A1513; €893). As none of the three studies mentioned ${ }^{1}{ }^{10}$ provides a detailed subdivision of the reported costs it is difficult to determine the reasons for the differences in OOPE. There is, however, evidence that the insurance coverage for health services is most comprehensive in countries like Germany and Switzerland, ${ }^{20}$ which might explain a large part of that difference.

Within our study by far the most important OOPE cost domain is "non-physician service utilisation". This includes natural healers as well as psychological therapy, occupational therapy, physiotherapy, and balneotherapy. While it is well known that patients are willing to spend considerable amounts for complementary and alternative medical treatments, ${ }^{21}$ the high OOPE for physiotherapy (€115 per patient and year) was unexpected. However, as recently shown in ankylosing spondylitis, similar values are observed at least in Belgium: the respective OOPE for physiotherapy was $€ 102$ per patient and year, accounting for $26 \%$ of total OOPE in that population. ${ }^{7}$

Medication costs are by far the most important cost domain from a payer's perspective and account for $€ 1019$ per patient per year ( $44 \%$ of total direct rheumatoid arthritis related costs from the payer's perspective).$^{16}$ It is well known, that from a consumer perspective OOPE for medication is less dominant. ${ }^{22}$ In our study, OOPE for medication resulted in $€ 99$ per patient and year (24\% of total direct rheumatoid arthritis related costs from the patients' perspective). There are no published data that specifically address rheumatoid arthritis related OOPE for medication. However, our results

Table 4 Rheumatoid arthritis related patient co-payment $(€)$ per patient-year by cost domains (base case analysis)

\begin{tabular}{|c|c|c|c|c|}
\hline Cost domain & Mean (SEM) (€) & $\begin{array}{l}\text { Percentage of total co- } \\
\text { payment }\end{array}$ & Median $(€)$ & Range $(€)$ \\
\hline Visits to physicians & $38.40(0.6)$ & 9.2 & 40 & 0 to 40 \\
\hline Non-physician service utilisation & $194.40(24.2)$ & 46.6 & 90 & 0 to 1852.5 \\
\hline Natural healer & $1.60(0.9)$ & 0.4 & 0 & 0 to 90 \\
\hline Psychological therapy & $4.00(2.7)$ & 1.0 & 0 & 0 to 360 \\
\hline Occupational therapy & $11.10(3.0)$ & 2.7 & 0 & 0 to 248 \\
\hline Physiotherapy & $114.80(16.8)$ & 27.5 & 7.5 & 0 to 1178 \\
\hline Balneotherapy & $63.00(11.0)$ & 15.1 & 0 & 0 to 90 \\
\hline Medication & $99.00(6.1)$ & 23.7 & 82.5 & 7.5 to 427.5 \\
\hline DMARD & $35.20(3.7)$ & 8.4 & 26 & 0 to 300 \\
\hline Steroids & $22.70(1.7)$ & 5.4 & 22.5 & 0 to 105 \\
\hline NSAID & $20.80(2.0)$ & 5.0 & 15 & 0 to 135 \\
\hline Osteoporosis medication & $13.70(1.4)$ & 3.3 & 7.5 & 0 to 60 \\
\hline Analgesics & $6.60(1.5)$ & 1.6 & 0 & 0 to 135 \\
\hline Devices and aids & $5.10(0.8)$ & 1.2 & 0 & 0 to 45 \\
\hline Hospital facilities & $24.00(5.6)$ & 5.8 & 0 & 0 to 280 \\
\hline Transportation & $56.20(17.4)$ & 13.5 & 0 & 0 to 1536 \\
\hline Total & $417.20(38.8)$ & 100 & 271.2 & 52.5 to 2753.1 \\
\hline
\end{tabular}


Table 5 Sensitivity analysis for rheumatoid arthritis related patient co-payment $(€)$ per patient-year for selected cost domains

\begin{tabular}{lrrl}
\hline Cost domain & Mean (SEM) & Median & Range \\
\hline Non-physician service utilisation & & \\
Low case & $129.6(16.1)$ & 60 & 0 to 1235 \\
High case & $259.3(32.3)$ & 120 & 0 to 2470 \\
Medication & & & \\
Low case & $66.0(4.1)$ & 55 & 5 to 285 \\
High case & $110.7(7.1)$ & 90 & 7.5 to 527.5 \\
\hline
\end{tabular}

are comparable to the reported OOPE of ( $€ 72$ per patient and year; $18 \%$ of total OOPE) for medication in ankylosing spondylitis in Belgium. ${ }^{7}$

Other domains, which each accounted for $<15 \%$ of total OOPE in our study, were "visits to physicians" (9\% of total OOPE), "hospital facilities" (6\% of total OOPE), "transportation" (13.5\% of total OOPE), and "devices and aids" (1\% of total OOPE). With regard to physician visits we identified a very low variance (SEM 0.6; SD 6.7), while the variance of transportation costs was very high (SEM 17.4; SD 202.9). Taking into account the skewed distribution pattern of transportation costs (three patients incurring costs of $>€ 1000$ per patient and year), the data within that cost domain have to be interpreted with caution .

Concerning co-payment, a major challenge is in the differentiation of rheumatoid arthritis $v$ non-rheumatoid arthritis related co-payments. In the present study, we aimed to discriminate rheumatoid arthritis related from nonrheumatoid arthritis related co-payments. The total patient expenditure is therefore most probably underestimated.

Co-payment regulations as per January 2004 introduced the special recognition of patients with chronic illnesses such as rheumatoid arthritis. For those patients total co-payment per annum is limited to a maximum of $1 \%$ of their gross income. As we have no valid data of the patients' real household incomes in the cohort investigated, we could not estimate how many patients would have to contribute less than the calculated OOPE of $€ 417$. It is likely that patients with rheumatoid arthritis in Germany benefit from this new co-payment regulation.

During this study, some areas of interest were identified that require further research. First, generally speaking, all Western health care systems try to limit public expenditure. Transferring parts of the cost to the patients is a common tool for reducing the burden on public budgets. However, the extent to which such transfers affect the consumption of health care, and the elements involved (that is, essential versus non-essential healthcare), remains to be explored. Second, collection of patient co-payment data is a difficult task as the access to correct and comprehensive data through a single data source is impossible. We therefore had to rely on data from a variety of sources that included payer derived utilisation data as well as patient questionnaires. While it has been shown that patient questionnaires are valid and reliable tools for some specific cost domains, ${ }^{17}$ it remains to be explored how valid and reliable are patients' reports of their own OOPE.

A limitation in the generalisability of the presented costing study is the selection of the study sample. The identification of patients was done by consultant rheumatologists - that is, all patients were receiving rheumatologist care. We did not examine OOPE in patients solely receiving general practitioner care. Furthermore, all patients had to be insured by the same health insurance scheme, the AOKN. We did not include patients covered by other insurance plans, or patients in the higher income strata who may be members of one of the private health insurance schemes. Finally, co-payment differs across countries owing to different health care systems, specific reimbursement systems, and obligatory premiums. Thus data from this study cannot be generalised, and comparisons of OOPE between countries should be made with caution.

\section{Conclusions}

Our study shows that rheumatoid arthritis is associated with substantial out of pocket expenditure, causing a considerable economic burden for patients with rheumatoid arthritis. The patients' out of pocket expenditure contributes significantly to the total health care expenditure in rheumatoid arthritis, and the patient perspective should be taken into account when calculating the overall direct costs of rheumatoid arthritis from a societal point of view.

\section{ACKNOWLEDGEMENTS}

We thank Brigitte Käser and Markus Dehning from the AOKN and Ernst Weinhold from the KVN for their encouraging support in realising the costing study. The study team gratefully acknowledges Volker Kück and Rainer Schubert from the AOKN for their continuous support with the transfer and management of the data.

\section{Authors' affiliations}

J L Hülsemann, S Merkesdal, S Zeh, S Handelmann, H Zeidler, J Ruof*, Division of Rheumatology, Hannover Medical School, Hannover, Germany

T Mittendorf, J M von der Schulenburg, Centre for Health Economics, University of Hannover, Hannover, Germany

*JLH and JR contributed equally to this paper

\section{REFERENCES}

1 Alexander CG, Casalino LP, Meltzer DO. Patient-physician communication about out-of-pocket costs. JAMA 2003;290:953-8.

2 Hwang W, Weller W, Ireys H, Anderson G. Out-of-pocket medical spending for care of chronic conditions. Health Aff (Millwood) 2001;20:267-78.

3 Langa KM, Fendrick AM, Chernew ME, Kabeto MU, Paisley KL, Hayman JA. Out-of-pocket healthcare expenditures among older Americans with cancer. Value Health 2004;7:186-94.

4 Fautrel B, Guillemin F. Cost of illness studies in rheumatic diseases. Curr Opin Rheumatol 2002;14:121-6.

5 Cooper NJ. Economic burden of rheumatoid arthritis: a systematic review. Rheumatology 2000;39:28-33.

6 Merkesdal S, Ruof J, Mittendorf T, Mau W, Zeidler H. Health economic research in rheumatoid arthritis. Z Rheumatol 2002;61:21-9.

7 Boonen A, van der Heijde D, Landewe R, Guillemin F, Spoorenberg A, Schouten $\mathrm{H}$, et al. Costs of ankylosing spondylitis in three European countries: the patient's perspective. Ann Rheum Dis 2003:62:741-7.

8 Lapsley HM, March LM, Tribe KL, Cross MJ, Brooks PM. Living with osteoarthritis: patient expenditures, health status, and social impact. Arthritis Care Res 2001;45:301-6.

9 Lapsley HM, March LM, Tribe KL, Cross MJ, Courtenay BG, Brooks PM. Living with rheumatoid arthritis: expenditures, health status, and social impact on patients. Ann Rheum Dis 2002;61:818-21.

10 Liang MH, Larson M, Thompson M. Costs and outcomes in rheumatoid arthritis and osteoarthritis. Arthritis Rheum 1984;27:522-9.

11 Cooper NJ, Mugford M, Symmons DPM, Barrett EM, Scott DGI. Total costs and predictors of costs in individuals with early inflammatory polyarthritis: a community-based prospective study. Rheumatology 2002;41:767-74.

12 Hülsemann JL, Mattussek S, Hennig H, Stucki G. Das Qualitatsmanagemen der Therapie der chronischen Polyarthritis in der rheumatologischen Praxis. Z Arztl Fortbilt Qualitatssich 2003;97:383-90.

13 Uitz E, Fransen J, Langenegger, Stucki G. Clinical quality management in rheumatoid arthritis: putting theory into practice. Swiss clinical management in rheumatoid arthritis. Rheumatology 2000;39:542-9.

14 Arnett FC, Edworthy SM, Bloch DA, McShane DJ, Fries JF, Cooper NS, et al. The American Association 1987 revised criteria for the classifications of rheumatoid arthritis. Arthritis Rheum 1988;31:315-24.

15 Mittendorf T, Merkesdal S, Zeidler H, Graf von der Schulenburg JM, Ruof J. Costs of ambulatory care for RA patients in Germany. Med klin (Munich) 2005; 100:255-61. 
16 Ruof J, Hulsemann JL, Mittendorf T, Handelmann S, von der Schulenburg JM, Zeidler $\mathrm{H}$, et al. Costs of rheumatoid arthritis in Germany: a micro-costing approach based on objective data sources. Ann Rheum Dis 2003;62:544-50.

17 Ruof J, Hulsemann JL, Mittendorf T, Handelmann S, von der Schulenburg JM, Zeidler $\mathrm{H}$, et al. Patient-reported health care utilization data in rheumatoid arthritis: what level of detail is required? Arthritis Rheum 2004;51:774-81.

18 Merkesdal S, Ruof J, Hulsemann JL, Maetzel A, Schoffski O, Mau W, et al. Development of a matrix of cost domains in economic evaluation of rheumatoid arthritis. J Rheumatol 2001;28:657-61.
19 Brosius G, Brosius F. SPSS base system and professional statistics. Koesel, Kempten: International Thomson Publishing, 1995.

20 Polikowski M, Santos-Eggimann B. How comprehensive are the basic packages of health services? An international comparison of six health insurance systems. J Health Serv Res Policy 2002:7:133-42.

21 Bridvevaux IP. A survey of patients' out-of-pocket payments for complementary and alternative medicine therapies. Complement Ther Med 2004; 12:48-50.

22 Lee JA, McKercher PL. Statistical comparison of consumer drug expenditures and discretionary purchases to assess drug affordability. Clin Ther 2002;24:1003-12

\section{Clinical Evidence - Call for contributors}

Clinical Evidence is a regularly updated evidence-based journal available worldwide both as a paper version and on the internet. Clinical Evidence needs to recruit a number of new contributors. Contributors are healthcare professionals or epidemiologists with experience in evidence-based medicine and the ability to write in a concise and structured way.

Areas for which we are currently seeking authors:

- Child health: nocturnal enuresis

- Eye disorders: bacterial conjunctivitis

- Male health: prostate cancer (metastatic)

- Women's health: pre-menstrual syndrome; pyelonephritis in non-pregnant women

However, we are always looking for others, so do not let this list discourage you.

Being a contributor involves:

- Selecting from a validated, screened search (performed by in-house Information Specialists) epidemiologically sound studies for inclusion.

- Documenting your decisions about which studies to include on an inclusion and exclusion form, which we keep on file.

- Writing the text to a highly structured template (about 1500-3000 words), using evidence from the final studies chosen, within 8-10 weeks of receiving the literature search.

- Working with Clinical Evidence editors to ensure that the final text meets epidemiological and style standards.

- Updating the text every six months using any new, sound evidence that becomes available. The Clinical Evidence in-house team will conduct the searches for contributors; your task is simply to filter out high quality studies and incorporate them in the existing text.

- To expand the topic to include a new question about once every 12-18 months.

If you would like to become a contributor for Clinical Evidence or require more information about what this involves please send your contact details and a copy of your CV, clearly stating the clinical area you are interested in, to Klara Brunnhuber (kbrunnhuber@ bmigroup.com).

\section{Call for peer reviewers}

Clinical Evidence also needs to recruit a number of new peer reviewers specifically with an interest in the clinical areas stated above, and also others related to general practice. Peer reviewers are healthcare professionals or epidemiologists with experience in evidence-based medicine. As a peer reviewer you would be asked for your views on the clinical relevance, validity, and accessibility of specific topics within the journal, and their usefulness to the intended audience (international generalists and healthcare professionals, possibly with limited statistical knowledge). Topics are usually 1500-3000 words in length and we would ask you to review between 2-5 topics per year. The peer review process takes place throughout the year, and our turnaround time for each review is ideally 10-14 days.

If you are interested in becoming a peer reviewer for Clinical Evidence, please complete the peer review questionnaire at www.clinicalevidence.com or contact Klara Brunnhuber (kbrunnhuber@bmigroup.com). 